\title{
Empirical Research on the Fault Criterion of ISPs' Torts
}

\author{
Xie Ziwei ${ }^{1, a}$ \\ ${ }^{1}$ Department of Marx' s law, Wuhan University of Science and Technology, Wuhan 430065, China \\ awustxieziwei@foxmail.com
}

Keywords: ISP; fault; criterion

Abstract. To determine the fault of Internet service providers (ISPs)' network information torts is a core issue to judge whether they should bear tort liability. In judicial practice, whether ISPs are at fault often depends on whether they violate the duty of care. However, due to imperfect legislation, judges must exert discretion in many fields of network torts that are not covered by law, which makes the judgment of ISPs' faults subject to different criteria in different cases.

\section{Introduction}

Since the 1980s, Internet technology has increased rapidly. It connects people all over the world together to share data and information. It is also increasingly common to communicate works through the Internet. According to statistics, in Q1 of 2014, Beijing First Intermediate People' s Court accepted a total of 253 copyright tort cases, up 120\% from a year earlier. Among them, 237 cases were involved in network copyright, accounting for $93.7 \%$. Among these cases, more than $80 \%$ of cases sued ISPs.

To keep up with the pace of the rapid development of Internet and cater to the international attention to intellectual property rights, China has never stopped Internet-related legislations. Among them, adjusting the relationship between copyright owner, ISPs and network users has become a problem which lawmakers must solve carefully in the process of Internet technology development, while "fault" criterion is the key to solving this problem. In copyright tort cases, judging whether an infringer is at fault or not in a correct way is an important link for the trial of such cases. However, the provision on the fault criterion of ISPs in Tort Liability Law in 2010 is just a principled provision. As a result, scholars and judges vary in the interpretation of the fault criterion. For this end, this article starts from real evidence and analyzes the gap between fault criterion in practice and in legislation using different cases.

\section{From the Abstract Duty of Care to Concrete Rule to Notify Deletion}

In judicial practice, the court generally believes that a tort that an infringer commits on the Internet is necessarily associated with information network. Inevitably, an ISP provides facilities, information, mediation, access and other technical services for the infringer' $\mathrm{s}$ torts. To identify whether this behavior constitute a kind of indirect tort or not, it is vital to judge the subjective fault of ISP. However, since there are no concrete rules on the fault judgment of network torts, the court judges faults from abstract principles extracted from legal provisions. Concrete facts and the nature of ISPs, etc. are at the judge' $s$ discretion. In this way, whether ISP has fulfilled its duty of due care is clarified.

In 2000, for the first time, Article 5 of Interpretation on Network Copyright stipulated the preliminary notice and removal procedures. Although concrete rules are still imperfect, the court has already had laws to abide to judge whether an ISP is at fault. For example, in Sony Music v. Beijing Shiji Yuebo Technology Co., Ltd. for infringing the copyright of sound recording in 2004, the court analyzed whether an ISP had a duty of care according to its specific behavior, subjective fault, objective consequence and many other factors, as well as the principle of consistency between rights and obligations, so as judge whether the ISP had a fault. The court also had investigated the business nature and professional ability of ISP in fault judgment. In the second instance of the above case, the 
court emphasized the defendant' $\mathrm{s}$ professionalism and professional ability and it was supposed to bear higher duty of care for legitimacy.

When an ISP' $s$ behavior has a legal basis, the court believes that the ISP has fulfilled its duty of due care. The legal basis can be explicit provisions in law. For example, in Zhang Xiaolu v. Beijing Kewen Cambridge Books Co., Ltd. for infringing copyright, the court argued that according to Chinese law, if the duplicate seller can prove that the duplicate it sold had a legitimate source, it didn' t have to bear any legal liability.

In 2006, Regulation on the Protection of the Right to Communicate Works to the Public over Information Networks was issued. China cited the safe harbor rule in the U.S. Digital Millennium Copyright Act. Thereby, the rule to notify deletion was formally established in the field of right to network transmission. This regulation also made specific provisions on the operating principle of notification rule, the content requirements of right notification, the legal obligations and legal liabilities of ISPs, etc. and provided an explicit legal basis to handle such cases in judicial practice.

In practice, the court has already begun to directly cite the rule of notification for trial. For example, in Wen Xiaoyang v. Beijing Alibaba Information Technology Co., Ltd. for infringing copyright, the court held that the search link service provider shall delink when receiving the obligee' s legitimate notice or bear corresponding legal consequences when he knew or was supposed to know that the linked content infringed rights.

Again, Paras. 2 and 3 in Article 36, Tort Liability Law in 2010 introduced the rule to notify deletion. The application scope of this rule was extended to all types of civil rights and interests within the protection scope of this law and established the status of the rule to notify as a general rule in network tort cases. In Universal Music Group v. Beijing Alibaba Information Technology Co., Ltd. for infringing the neighboring right of copyright, the court believed that although the ISP completely delinked relevant links for which the plaintiff provided URLs upon notice, it delayed in exercising the duty to delete other infringing search links related to the song in question and connived at the occurrence of tort results, so it had a subjective fault in expanding the damage.

\section{Inconsistent Fault Criteria In Judicial Practice}

The problem of the tort of the right to communicate works over network shall first apply to Tort Liability Law enforced in 2010. But the rule to notify deletion in Tort Liability Law is overly principled. There are noticeable institutional defects in the detailed design of system, but no corresponding "supporting system" as a guarantee, such as the notification conditions, counternotification and accountability for wrong notices. Besides, despite Regulation on the Protection of the Right to Communicate Works to the Public over Information Networks, the imperfect concrete rules, the legal status of administrative regulations and other factors also made different courts, even different judges, followed inconsistent fault criteria in judicial practice.

Inconsistent content and form of notice

Article 14 of Regulation on the Protection of the Right to Communicate Works to the Public over Information Networks stipulated that a notice should contain the owner' s basic information, the name and network address of the infringed work to be deleted or delinked and preliminary evidence of tort. But Tort Liability Law didn' t make any requirements for notice. The notifier only needed to prove that he had issued a notice to an ISP, which can be used as one of the evidences to judge the subjective fault of ISP. As a result, judges varied in the judgment of whether the form and content of notice was proper.

In Shanghai Hantao Information Consulting Co., Ltd. v. Beijing Aibang Juxin Technology Co., Ltd. for infringing copyright, the court didn' $\mathrm{t}$ entirely follow the rule in Regulation on the Protection of the Right to Communicate Works to the Public over Information Networks and required that the plaintiff' s notice should contain "the name and network address of the infringed work to be deleted or delinked" , but considered the complexity and quantity of tort and judged from the plaintiff' s technical ability to implement and accomplish, as well as the severity of the defendant' 
s tort. However, in Wang Yajun v. Beijing eLong Information Technology Co., Ltd. for infringing the right to communicate works over information networks, the court believed that the form and content of notice can be simplified. As long as the form was proper, an ISP was not liable to examine whether the content constituted a tort or not.

Inconsistent fault criteria of internet service providers (ISPs)' $\mathrm{s}$ fulfillment of the duty of information disclosure

Article 13 of Regulation on the Protection of the Right to Communicate Works to the Public over Information Networks stipulated that "to investigate the tort of the right to communicate works to the public over information networks, an copyright administrator may require an ISP to provide the name (title), contact information and network address, etc. of an service object that was suspected of tort". It was thus clear that legislators believed that an ISP was obliged to save the data and information of service object. When the court retrieved relevant evidence and records, the ISP were obliged to provide the identity and contact information of a real infringer. In judicial practice, however, the court disagreed on whether an ISP fulfilled the duty of information disclosure and the fault criteria of ISPs' fulfillment of the duty of information disclosure.

In Qiao Tianfu v. Beijing Tiexue Technology Co., Ltd. for infringing copyright, the court argued that the provision in Article 5 of Interpretation on Network Copyright was applicable to ISPs which can' $t$ bear the duty of care for the legitimacy of the information that they had provided. If commercial websites failed to bear the duty of care for the legitimacy of the information that they had provided and didn' $\mathrm{t}$ disclose the information of the service object before litigation, then they constituted torts.

In Zhejiang Dongyang Tianshi Cultural Communication Co., Ltd. v. Beijing Baidu Wangxun Technology Co., Ltd. and Beijing Branch, China Telecom Co., Ltd. for infringing the right to communicate works over information networks, the court believed that when a certain IP address was suspected of large-scale tort, as long as the ISP disclosed information of the service object to the court during prosecution, it can be regarded to have fulfilled the duty of due care.

How to identify inconsistent criteria of "change" in Para. 2 in Article 22 of Regulation

Article 22 of Regulation on the Protection of the Right to Communicate Works to the Public over Information Networks stipulated that "If an ISP provides information storage space for a service objects for the latter to offer works, performance, sound recording or video recording to the public and meet the following requirements, they shall not be liable for compensation: $\cdots$ (II) not to change the works, performance, sound recording or video recording offered by the service object...." Therein, the court interprets "change" in different ways.

In Beijing Guangdian Weiye Film and TV Culture Center v. Ku6 Information Technology Co., Ltd. for infringing copyright, the court believed that an ISP attaching their own logos to the plaintiff' s works had indicated the source of works and "changed" the works provided by the service object. In another case, which was identical with this one, Beijing Sun Shine Culture Communication Co., Ltd. v. Beijing Fone Net Information Technology Co., Ltd. for infringing the right to communicate works over information networks, the court found that the logo attachment of ISP cannot prove the real source of the film and TV works in question. The court didn' t regard watermark as "changing" the work offered by the service object.

In the above two cases, obviously the judgment of the second case seemed more reasonable, the word "change" in Regulation on the Protection of the Right to Communicate Works to the Public over Information Networks should not be taken literally. Since Regulation was transplanted from the U.S. Digital Millennium Copyright Act, one should notice that word "change" was borrowed from Paras. (a) and (b) in Article 512 of Digital Millennium Copyright Act: "not to change the content of works" . The watermarking of uploaded works by a video website didn' $t$ destroy the integrity of videos or influence the average user' $\mathrm{s}$ experience. So watermarking shall not be considered as changing the uploaded works. 
Inconsistent identification of the reasonability of web cache providing behavior

Article 5 of Provisions on Some Issues about Applicable Laws for the Supreme People's Court to Hear Civil Disputes over the Right to Communicate Works Over Information Networks, “If an ISP provides relevant works to the public in the way of web cache and thumbnail, etc. and replaces other ISPs materially, the people' s court should identify that they constitute torts." . This rule is a basis to judge whether the existing web cache providing behavior is at fault or not. But in judicial practice, the courts often disagree on the interpretation of whether web cache is to offer relevant works to the public instead of other ISPs materially.

In Beijing Sanmianxiang Copyright Agency Co., Ltd. v. Beijing Qihoo Technology Co., Ltd. and other copyright ownership and tort disputes, from the perspective of user choice, the court believed that when users were browsing pages, their first choice would be browsing the original page. But web cache was a kind of use out of special needs. Usually, it cannot replace the original page materially, so it didn' t belong to torts.

In the famous Zhejiang Pan-Asia Electronic Commerce Co., Ltd. v. Beijing Baidu Wangxun Technology Co., Ltd. for infringing copyright, the court believed that change of the display mode of lyric "cache" didn' t change the way users directly got lyrics from Beidu pages. It completely replaced a third-party website to offer lyrics and objectively let users got lyrics directly from its server, which was sufficient to affect the market interests of the third party that provided lyrics. It can be seen that the court mainly judged the responsibility of web cache providing behavior from the development of current technology, the irreplaceability of web cache to the social public, the general choice of rational users and whether it was sufficient to affect the market economic benefits of the third party.

\section{References}

[1] Wang, Yong and Chang Ming. A Case Study of Network Torts [M]. Beijing: China Democratic and Legal Publishing House, 2009:1.

[2] Si, Xiao and Fan, Luqiong. Legal Regulations on the Abuse of "Notification-Deletion" Rule in the Domain of Intellectual Property Rights [J] Electronics Intellectual Property, 2015:91 92.

[3] Wang, Liming. On Doctrine of Notice in Cyber Torts [J] Northern Legal Science, 2014(8):36.

[4] Wang, Shengming. The Definition of Tort Liability Law in the People' s Republic of China [M]. Beijing: China Law Press, 2010:191.

[5] Jin, Bo. Research on the Accountability Principle of Intellectual Property Torts [D], Anhui University, 2005:33.

[6] Fang, Zhigang. The Illegality of Network Infringer ISPs' Behaviors from the Perspective of Rights and Obligations [J] Journal of Yunan University Law Edition, 2004(1):91 92.

[7] Wang, Qian. Reexamining the Copyright Infringement of Video Sharing Websites [J]. Studies in Law and Business, 2010(1):90.

[8] Song, Zhe. Study on the Duty of Care of Internet Service Providers [M]. Beijing: Beijing University Press, 2014: 10.

[9] Chen, Zhixing and Chang Ming. Internet Service Providers: How to "Hide" in a Haven of Intellectual Property Disputes [N] People’ s Court Daily, 2004-4-27(3). 